\title{
Research on Multi Energy Data Transaction Model Based on Vector Evaluate Genetic Algorithm
}

\author{
Zheng Wang ${ }^{1, *}$, Ling Jiang ${ }^{1},{\text { Yongbiao } \text { Yang }^{2} \text {, Tianchun Xiang }}^{1}$, Jie Song ${ }^{2}$, Shengjun Yan ${ }^{2}$ \\ ${ }^{1}$ State Grid Tianjin Electric Power Company, Tianjin 300010, China \\ ${ }^{2}$ NARI Technology Development Co., Ltd., Nanjing 211106, China
}

\begin{abstract}
With the development of smart grid construction and the innovation of the business mode of State Grid, power systems business including generation, transmission, transformation, distribution, consumption and dispatching, produces a large amount of data every day. At the same time, power system is also one of the important application areas of big data. Based on the smart grid construction of Sino-Singapore Tianjin Eco-city, the model of big data transaction between power system and other industries is researched. First, the sources and characteristics of muti energy data in Sino-Singapore Tianjin Eco-city are analysed. Furthermore, this paper proposes a big data transaction model turned into multi attribute negotiation, and the utility function of multi attribute negotiation is proposed to reflect the correlation degree between different attributes. Finally, a multi objective optimization algorithm based on vector evaluated genetic algorithm for big data transaction of smart grid is given, so as to realize a win-win situation between buyers and sellers.
\end{abstract}

\section{Introduction}

State Grid investment in smart grid innovation demonstration area is used to realise the integration of energy and information interconnection, improve the utilization efficiency of urban comprehensive energy, innovate grid operation service mode and support smart city construction[1]-[2]. In 2011, Tianjin electric power company had built smart grid demonstration project "Sino-Singapore Tianjin Eco-city" . It includes 12 sub items, such as distributed generation, microgrid , distribution automation, etc, with a concentrated demonstration of advanced technology in the field of intelligent power distribution, generation,consuption and information communication[3]-[5]. Since the operation of above projects, massive data has been contained in the relevant business system's internal database, including new energy power generation data, electric vehicle charging and discharging data, power grid on-line monitoring data, consuption data, power quality data, etc. The massive data from a wide variety of sources, is a typical power big data[6]-[8].

Power big data combined with municipal, transportation, meteorology, economy and other industry data, can be analysed by data mining, machine learning, parallel computing, flow calculation and other "big data" technology to dig out critical information with higher added values, and then provide a solid data base and space for the power resource optimal allocation, the improvement of energy efficiency, the higher quality service and the auxiliary social management [9]-[10].

However, the amount of data stored in various industries, including electricity,is increasing sharply with a growth rate of more than $50 \%$. Due to the lack of standardized data sharing and exchange channels, it is difficult to form a data sharing between different industries,and thus data trading platform and even the exchange has become an urgent need. At present, the research on the big data transaction mechanism is still in the initial stage. From the perspective of new institutional economics, the paper studies the mechanism of large data trading in [11], and several factors that affect the data transaction cost are presented, but it has not been studied in the game process of data transaction. The paper studies the bilateral transaction characteristics and pricing mechanism based on cloud computing services market in [12]-[14], however, due to the large difference between the problem of resource type and real time, and big data transaction, it can not be directly applied into big data transaction process. The paper presents a trading mechanism that stimulates the buyer and seller to reveal the true data information based on big data computing service in[15]. but the "win-win" result of the transaction process is not realized.

Based on the smart grid construction of SinoSingapore Tianjin Eco-city, the sources and characteristics are analysed, and the model of big data transaction between power system and other industries is studied in this paper. A multi objective optimization algorithm based on vector evaluated genetic algorithm for big data transaction of smart grid is given, so as to realize a winwin situation between buyers and sellers.

\section{Sources, characteristics and application scenarios of multi energy big data}

Power big data applications in Sino-Singapore Tianjin Eco-city inlcude 12 sub items, such as distributed power access, energy storage system, distribution automation and so on. At the same time, electric power system also need to obtain big data from municipal, traffic, meteorology, economy and other industries. These data sources cover management operations including dispatching, operation and overhaul, marketing and power grid monitoring information, and industry information which is related to the production and operation of power system. The data includes diffferent kind of types such as structured, semi-structured and unstructured, and their update frequency range from second to month.

After data fusion from different time scales, using data mining, machine learning and clustering analysis, and other algorithms, accquires application scenaries of multi 
energy data in Sino-Singapore Tianjin Eco-city, within the computational framework such as parallel computing, flow calculation, and mixed calculation. For example, electric load data can be used to predict and evaluate the development of the national economy. On the contrary, the data of the national economy and the growth of the motor vehicle can also be used as the basis for networking and operation mode of the power system.

\section{Conceptual model of big data transaction}

Because of the great value from big data applications, it is necessary to obtain mass data from other industries through data transactions, and thus be information sources of data fusion in a certain industry. This application has laid the foundation of data transaction. Big data transaction, specifically, is a transaction on the ownership and rights to use of data. Traditional commodity trading and electronic business transactions, such as pricing and auction market mechanism, can not meet the needs of big data transactions[16]. Therefore, how to form a large data trading market and establish an effective model and trade mechanism to support data transaction process, become an important issue in the application mode of multi energy big data.

This paper defines the large data transaction model based on the big data market, as shown in Figure 1.

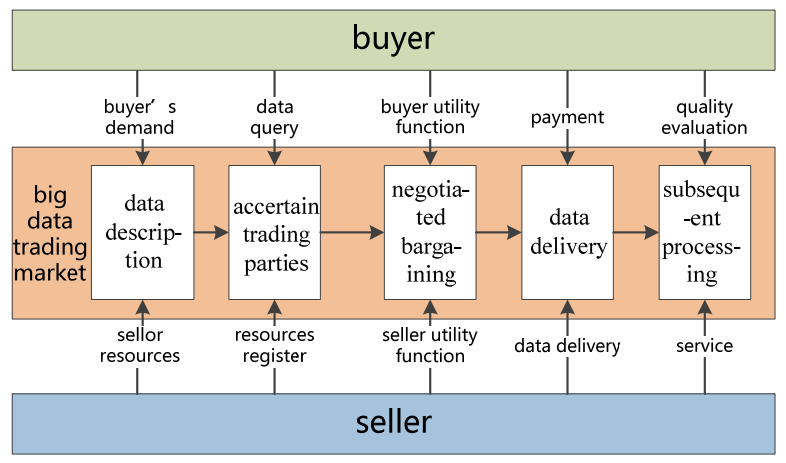

Figure1. Big data transaction model based on big data exchange market

(1) Data description: Buyers and sellers will abstract the key attributes of the required data and data resources, and determines the type and range of attributes, and describes it by a structured language.

(2) Accertain trading parties: Sellers register data resource in the data market and then form a data directory. Meanwhile, buyers search trade goals and candidate objects.

(3) Negotiated bargaining: Trading parties carry out proposals based on their own data transactions. Big data transaction object with different attribute values calculate the utility value of proposals according to their own utility function.

(4) Data delievery: In this stage, except delivering data at a specified time according to the service contract, data service providers also need to configure the data services in accordance with the service contract. And data users need to complete the payment accoding to the contract.

(5) Subsequent processing: In this stage, the mission is the subsequent processing tasks after data delivery, such as a mutual evaluation between data users and providers, and so on.

From Figure 1, it can be seen that the bargaining is the main link of the big data transactions, but also the focus of this paper. As the main body of the big data transaction, the quality description of the data is the basis for buyers and sellers to determine the transaction intention and negotiated price. The quality of data can be abstracted into several data attributes. The data attributes include inner independent attributes(precision, sampling frequency, time span, etc) as well as correlation degree between attributes. For the above data attribute features, the object of big data transactions can be abstracted as:

(1)where, is a data bargaining object within a round of negotiated bargaining. And a big data bargaining process contains $k$ rounds. The vector means $n$ attributes of the object of negotiation between the two parties, while means the vector of attribute values in a round of negotiation. The value scope of each element of the ndimensional vector is .

Both parties change the data attributes to form a multi attribute negotiation issues within the limits of their acceptance in each negotiation process. After $k$ rounds of negotiation, the seller and buyer achieve the final data agreement, so as to complete the transaction. During negotiation, utility value is adopted to measure the degree of their satisfaction to multi attribute data. And utility value can be obtained by the utility function with the data attribute as a parameter. In the utility function, a attribute can be divided into two types, namely positive or negative attributes. The higher value of positive attributes results in buyers' or sellers' more satisfaction with the transaction. But buyers' or sellers' judgment for the same type of attribute is just opposite, namely a positive attribute for seller is a negative attribute for buyer.

Multi attribute utility function is constructed by multi attribute variables and is also a function used to evluate the utility value of each proposal for users [16]. This paper proposes a utility function which reflect the relevance of attributes.

(2)where, is the utility value calculated from multiple attribute issue by buyers or sellers in $i$-round of negotiated bargaining. is the normalized value of the jth attribute in $t$ he n-dimensional attribute vector by buyers or sellers. is a weight evaluation for the jth attribute. is the correlation degree between the jth and kth attribute. is the normalized value of the kth attribute.The normalization process of an d can be calculated by the following steps:

(3)For the same attribute $j$, because of its difference of attribute types for sellers and buyers, that causes a different range of its value, a different evaluation weight for both sides, and thus exerts a different final impact on utility value. Therefor, optimization algorithms are needed to complete transaction through multi attribute negotiation automatically. 


\section{Fair negotiated bargaining based on Vector Evaluate Genetic Algorithm}

MOGA(Multi Objective Genetic Algorithm) is an application of genetic algorithm to deal with multiobjective optimization problems[16]- [17]. Compared with traditional methods, MOGA can not only deal with large scale problems, but also is not restricted by the characteristics of the problem(linearity, continuity, differentiability, etc), so as to search the global optimal solution. VEGA(Vector Evaluate Genetic Algorithm) is a new multi objective advanced algorithm used to search a set of non-inferior solution proposed by Schaffer in 1984 .

VEGA adopts proportional selection mechanism and produces a sub-population corresponding to each sub objective function. If the number of sub objective of multi objective issues is $k$, that will produce $k$ sub-populations, and the scale of each sub-population is $N / k$, where $N$ is the scale of the whole population. Each sub objective function completes the selection independently in their own subpopulation, and then conduct crossover and mutation after the results of selection enter into cross cell, and finally the non-inferior solution to a certain problem is acquired[18]-[19].

To big data multi attribute negotiation transactions, sub population includes the buyer and seller, in other words, the number of population is 2. Each issues of the multiple attribute negotiation is represented by a certain chromosome encoding attributes. Each generation of populations is made up of such $\mathrm{N}$ chromosomes. Through several generations of genetic operations, the final chromosome will tend to be the Pareto optimal solution. The flow chart of fair negotiated bargaining based on VEGA is shown in Figure 3.

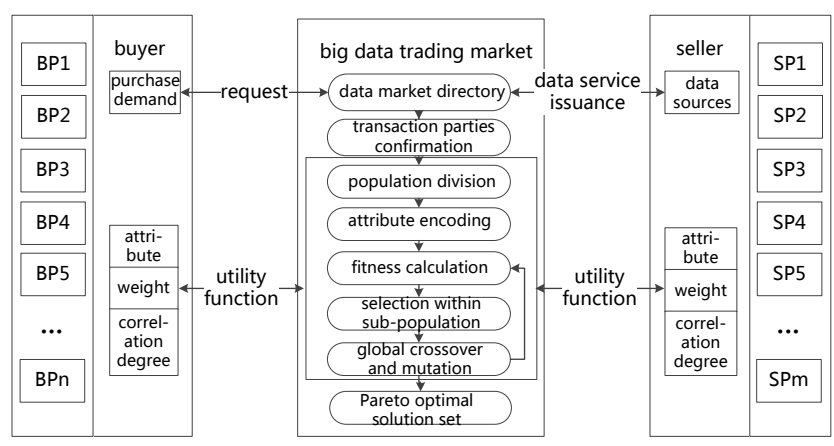

Figure2.Fair negotiated bargaining algorithm of big data tranction based on VEGA

According to utility function above, the optimization objective of VEGA can be expressed as:

(4)where, is buyer's utility value, and is seller's utility value. is buyer's proposal to data attribute value in the pr ocess of each round of negotiation, while is seller's prop osal. Multi objective optimization based on VEGA will a cquire a group of Pareto optimal solution sets. Finally, se ller and buyer should determine the price on the base of $i$ $\mathrm{t}$, and will achieve the“win-win”goal.

\section{Experiment and analysis}

In order to verify the validity of the proposed transaction model and fair negotiation algorithm in this paper, MATLAB was adopted to simulate the transaction of PV data in the data trading market of Sino-Singapore Tianjin Eco-city. Buyers may be consultant firms that need PV data to predict the developmemt of new energy industry, while the seller is State Grid who has PV dispatching data. The negotiated attributes include the precision of AC analog sampling data, and the time span of power generation data. Both of them are relevant with facilities quantity. Experiments were carried out in three groups and the value range, evaluation weight and correlation degree are listed in table 1.

table1.Attribute parameters of buyers and sellers

\begin{tabular}{|c|c|c|c|c|c|}
\hline No. & attribute & $\begin{array}{l}\text { value } \\
\text { range }\end{array}$ & $\begin{array}{l}\text { weight } \\
\text { for } \\
\text { buyer }\end{array}$ & $\begin{array}{l}\text { weight } \\
\text { for } \\
\text { seller }\end{array}$ & $\begin{array}{l}\text { correlaton } \\
\text { degree }\end{array}$ \\
\hline \multirow[t]{7}{*}{1} & precision & group1 & group1 & group1 & \\
\hline & \multirow{2}{*}{$\begin{array}{l}\text { of AC } \\
\text { analog } \\
\text { sampling }\end{array}$} & {$[1,4]$} & 0.5 & 0.5 & \\
\hline & & & & & \\
\hline & & group2 & group2 & group2 & \\
\hline & \multirow[t]{3}{*}{$\left(A_{1}\right)$} & {$[1.8,4]$} & 0.6 & 0.4 & \\
\hline & & group3 & group3 & group3 & \\
\hline & & {$[2.5,4]$} & 0.7 & 0.3 & \\
\hline \multirow[t]{7}{*}{2} & \multirow{7}{*}{$\begin{array}{l}\text { time span } \\
\text { of power } \\
\text { generation } \\
\text { data } \\
\left(A_{2}\right)\end{array}$} & group1 & group1 & group1 & \\
\hline & & {$[1,5]$} & 0.6 & 0.4 & \\
\hline & & 7xmoun & ? & רroun & \\
\hline & & gгоир & group & group & \\
\hline & & {$[1.5,5]$} & 0.7 & 0.3 & \\
\hline & & group3 & group3 & group3 & \\
\hline & & {$[3,5]$} & 0.8 & 0.2 & \\
\hline \multirow[t]{6}{*}{3} & \multirow{6}{*}{$\begin{array}{l}\text { quantity } \\
\text { of power } \\
\text { generation } \\
\text { facilities } \\
\left(A_{3}\right)\end{array}$} & group1 & group1 & group1 & \multirow[t]{6}{*}{ - } \\
\hline & & {$[1,8]$} & 0.7 & 0.3 & \\
\hline & & group2 & group2 & group2 & \\
\hline & & {$[2.5,8]$} & 0.6 & 0.4 & \\
\hline & & group3 & group3 & group3 & \\
\hline & & {$[5,8]$} & 0.5 & 0.5 & \\
\hline
\end{tabular}

The parameters of the VEGA algorithm used in the experiment are shown in Table 2.

Table2. Parameters of the VEGA

\begin{tabular}{lll}
\hline No. & name & value \\
\hline 1 & Population Size & 300 \\
2 & Maximum of Generation & 60 \\
3 & Crossover Probability & 0.55 \\
4 & Mutation Probability & 0.43 \\
\hline
\end{tabular}


The experiment was simulated by MATLAB, and the result is presented in table 3 .

table3. Simulation result

\begin{tabular}{llllll}
\hline group & $A_{1}$ & $A_{2}$ & $A_{3}$ & $v_{\mathrm{b}}$ & $v_{\mathrm{s}}$ \\
\hline 1 & 1.0504 & 1.1019 & 1.0128 & 2.1784 & 1.4927 \\
2 & 2.031 & 1.8257 & 3.0871 & 5.2517 & 3.0545 \\
3 & 1.5012 & 3.5218 & 7.4521 & 10.0134 & 5.4951 \\
\hline
\end{tabular}

As can be seen in table 3, Using the VEGA algorithm can accomplish multi objective optimization to the utility function, and then acquire Pareto optimal solution sets. Meantime, in the case of the narrowed range of data attributes value, more accurate optimal attribute can be determined, and finally, the utility value of both parties can also be improved.

\section{Conclusion}

Based on the application of multi energy big data in SinoSingapore Tianjin Eco-city, combined with a large amount of literature and engineering experience, this paper proposes application scenarios of big data trading market, conceptual model and fair negotiated bargaining algorithm. MATLAB was adopted to design multi objective optimization algorithm based on VEGA and also several experiments were conducted to verify its validity. The results shows that the utility function and the multi objective optimization algorithm proposed in this paper can acquire a perfect data attribute value which makes a win-win situation for both parties. Finally, Based on the attribute value, the price of data transaction could be determined.

as a value-added service mode of smart grid based on Internet thinking, power data transaction will bring new business and profits for State Grid, and data fusion analysis of multi energy data will also bring more application scenarios for Sino-Singapore Tianjin Eco-city, and finally promote the development of energy utilization level and regional economics.

\section{Acknowledgements}

This work was supported by the Science and Technology Foundation of State Grid Corporation (SGTJDK00DWJS1500101).

\section{References}

[1] Cao junwei, Wan yuxi, Tu guoyu, etc. Information system Architecture for Smart Grids[J]. Chinese Journal of Computers, 2013(1): 144-167. (in Chinese)

[2] Hu xuehao. Smart Grid-A Development Trend of Future Power Grid[J]. Power System Technology, 2009(14): 1-5. (in Chinese)

[3] Yin qiang. Research on Sino-Singapore Tianjin EcoCity mode of operation[J]. Tianjin: Tianjin University of Technology, 2009. (in Chinese)

[4] Xie kai, Liu mingzhi, Yu jiancheng. Summary on smart grid integrated demonstration project of SinoSingapore Tianjin Eco-City[J]. Journal of Electric Power Science and Technology, 2011(1): 43-47. (in
Chinese)

[5] Li xiaoquan. Applications of Intelligent Power Equipment in Sino-Singapore Tianjin Eco-City Grid[D]. Baoding: North China Electric Power University, 2013. (in Chinese)

[6] Wang dewen, Song yaqi, Zhu yongli. Smart Grid information platform based on cloud computing[J]. Automation of Electric Power System, 2010(22): 712. (in Chinese)

[7] Song yaqi, Zhou guoliang, Zhu yongli. Present Status and Challenges of Big Data Processing in Smart Grid[J]. Power System Technology, 2013(4): 927935. (in Chinese)

[8] Rusitschka S, Eger K, Gerdes C. Smart grid data cloud: a model for utilizing cloud computing in the smart grid domain[C]. Smart Grid Communications (SmartGridComm), 2010 First IEEE International Conference. Gaithersburg, MD: IEEE, 2010: 483-488.

[9] Liu keyan, Sheng wanxing, Zhang dongxia, etc. Big Data Application Requirements and Scenario Analysis in Smart Distribution Network[J]. Proceedings of the CSEE, 2015(2): 287-293. (in Chinese)

[10] JiaWei Han, Micheline K, Jian P. Data mining: Concepts and technique[M]. 3rd ed. New York: Elsevier, 2011

[11] Wu jiang. A Preliminary Study of the Mechanism of Data Transaction-A View of New Institutional Economics[J]. Journal of Tianjin University of Commerce, 2015(3): 3-8. (in Chinese)

[12]Zhang rui. Research on pricing strategy of cloud computing services[D]. Shanghai: Donghua University, 2014. (in Chinese)

[13] Lu jiaocai. Study on contract negotiation based on negotiation mechanism of cloud resources trading[D]. Hangzhou: Zhejiang Gongshang University,2012. (in Chinese)

[14] Li Ming. Research on service negotiation algorithm and transaction process management in cloud service platform[D]. Jinan: Shandong University,2014. (in Chinese)

[15] Lena Mashayekhy, MahyarMovahedNejad, Daniel Grosu. A Two-Sided Market Mechanism for Trading Big Data Computing Commodities[C]. 2014 IEEE International Conference on Big Data. Bethesda, MD: IEEE, 2014: 153-158.

[16]Zhang chunyang, Chen zhuo, Wu qingtao. Study on Optimum Component Combination Based on Multiattribute Utility Function[J]. Communications Technology, 2010(6): 238-240. (in Chinese)

[17] Xu lei. The research and application of Multiobjective optimization problems based on genetic algorithms[D]. Changsha: Central South University, 2007. (in Chinese)

[18] Li lirong. The research about Multi-objective genetic algorithms to solving Pareto Front[D]. Xiangtan: Xiangtan University, 2003. (in Chinese)

[19]Zhou jiansong, Chen yi, Zhang xiaoli, etc. The evalution of Multi-objective optimization and program test based on vec-tor evaluated genetic algorithm[J]. Chinese Journal of Health Statistics, 2012(2): 181-186. (in Chinese) 